\title{
Relation Between Mastery Behavior in Infancy and Competence in Early Childhood
}

\author{
David J. Messer, Mary E. McCarthy, Susan McQuiston, Robert H. MacTurk, \\ Leon J. Yarrow, and Peter M. Vietze \\ Child and Family Research Section, Laboratory of Comparative Ethology, \\ National Institute of Child Health and Human Development, \\ National Institutes of Health, Bethesda, Maryland
}

\begin{abstract}
The failure of developmental tests in infancy to predict later competence may be because the tests ignore important dimensions of infant functioning. Yarrow and Pedersen (1976) have suggested that one such dimension could be mastery behavior, which involves persistence and investigation. Fiftythree infants were observed at 6 and 12 months during two 24-min play sessions. The Bayley Scales of Infant Development were given at 6 and 12 months, and the McCarthy Scales of Children's Abilities at 30 months. Measures of competence in infancy (successful task completion during play and the Bayley scores) were not strongly correlated with the 30-month McCarthy Scales. In contrast, infant mastery behavior during play strongly predicted McCarthy scores: The time spent investigating toys at 6 months, and persistence in solving tasks at 12 months, were behaviors significantly positively correlated with the McCarthy Scales. Thus, infant behaviors that predict later competence do not remain static, but change with age. More importantly, infants' mastery behavior appears to be a more effective predictor of later development than their competence with either toys or developmental tests.
\end{abstract}

The use of measures or observations made in infancy to predict later functioning is often considered an important topic of research in developmental psychology. The fascination with this topic may stem from a widespread conviction that early characteristics and experience are salient for later development. Prediction of later intellectual functioning has attracted particular interest because of its possible diagnostic value, and because it may assist identification of developmentally significant features of either infants' capabilities or their environment. However, studies with nondelayed children mostly have failed to find strong relations between scores on developmental tests in infancy and later intellectual functioning (Honzik, 1976; McCall, 1979). Only after children reach 2 years of age are high correlations usually found between test scores at different ages.

The lack of prediction between standardized infant tests and later standardized measures has led to questions about the validity of early developmental tests so that now the tendency is to regard them as assessments of early competence rather than of early intelligence. The debate about the concept of competence has been long, complex, and interesting. Even the pioneers of infant testing (Bayley, 1955; Gesell, 1925) admitted the limitations of relying on test results to describe the performance of children; they recognized that a single score did not adequately summarize

An earlier version of this article was presented at the 90th Annual Convention of the American Psychological Association by D. J. Messer, L. J. Yarrow, and P. M. Vietze.

Leon Yarrow's untimely death prevented him from seeing this finished article; however, we feel sure that in working on draft revisions, Lee derived great satisfaction from seeing the results of his conceptualizations about the role of mastery motivation in early competance.

Correspondence concerning this article should be addressed to David J. Messer, The Psychology Division, Hatfield Polytechnic, College Lane, Hatfield, Herts AL10 9AB, England. the complexity of cognitive functioning. Furthermore, the possibility has been raised that studying the process of infant activities may be a more useful indication of capacities than performance scores or achievement of successful outcomes (Yarrow \& Pedersen, 1976).

The interrelation between motivation and later competence has been the subject of speculation. White $(1959,1963)$ and Hunt $(1963,1965)$ both suggest that there is an intrinsic motivation to be competent, that the refinement and acquisition of skills provides a sense of satisfaction. Bruner (1973) has also discussed the link between early skilled activities, and the development of intention and competence. A related perspective is that feelings of effectiveness are influenced by a recognition that events are contingent on an infant's own actions (Bronson, 1971; Lewis \& Goldberg, 1969; Watson, 1966, 1972).

The postulation of a relation between intellectual functioning and the infant's motivation to be effective, to be competent, or to master is intuitively appealing. However, only a limited number of studies have directly examined this issue. Part of the reason for this may have been the difficulty in developing suitable methods to classify and describe these concepts. One attempt has been made by Yarrow and his associates to describe mastery behavior of infants in terms of the time they spend in various levels of task involvement. Mastery behavior can be considered to represent the infants' persistence and investigation of problems and objects. Significant correlations have been found between mastery behavior at 6 months and Bayley Scales of Infant Development scores at 12 months (Yarrow et al., 1983). Jennings, Yarrow, and Martin (1981) obtained measures of persistence in task-directed behaviors at 13 months, and McCarthy Scales of Children's Abilities scores at 31/2 years: For girls, persistence in task-directed behavior was found to be significantly correlated with later perceptual performance scores on the McCarthy Scale; no significant correlations occurred for boys. Other longitudinal 
Table 1

Codes and Percentage Duration of 6-Month and 12-Month Mastery Behavior

\begin{tabular}{|c|c|c|c|c|c|}
\hline Category & Behaviors & \multicolumn{2}{|c|}{6 Months } & \multicolumn{2}{|c|}{12 Months } \\
\hline Peripheral Exploration & $\begin{array}{l}\text { Only touch apparatus; only mouth apparatus; only } \\
\text { passively hold apparatus }\end{array}$ & 5.5 & 3.4 & 3.1 & 1.9 \\
\hline General Exploration & $\begin{array}{l}\text { Manipulate; examine; bang; shake; hit or bat; drop } \\
\text { object; reject object; offer, give; }\end{array}$ & 22.4 & 6.1 & 21.8 & 5.1 \\
\hline Goal-Directed Behavior & Goal-directed maneuver (correct); resets problem or task & 13.4 & 3.9 & 18.2 & 4.9 \\
\hline Success & $\begin{array}{l}\text { Effect produced; problem solved; motor task } \\
\text { accomplished }\end{array}$ & 7.8 & 2.0 & 7.0 & 3.1 \\
\hline
\end{tabular}

${ }^{a}$ Data for 53 subjects on the longitudinal study, percentage of total time; totals do not add to $100 \%$ because of nontask activities.

studies have reported different patterns of correlations between the sexes in the development of competence (Bayley \& Shaefer, 1964; Honzik, 1976; McCall, Hogarty, \& Hurlbert, 1972), which suggests these groups should be examined separately rather than combined.

In this study, infants' success on tasks were observed and standardized developmental test results were collected at 6 and again at 12 months. In addition, at both ages measures of mastery behavior were obtained; this allowed us to observe early forms of directed activities with objects. Developmental competence measures were obtained at 30 months, an age at which intellectual functioning has probably begun to stabilize. By examining the relation between early mastery and later competence, we hoped to begin to assess the relevance of mastery behavior to the process of development. In particular, we wanted to compare the effectiveness of mastery behavior and success on problems in predicting later competence. In this way, we hoped to obtain support for the idea that the way infants explore objects or accomplish tasks is a more relevant process for development than successful solution of problems.

\section{Method}

\section{Subjects}

The initial sample consisted of 75 firstborn infants, 38 boys and 37 girls from middle-income families. Only infants whose birth was uneventful, according to parental report, were included in the study. Families were recruited for participation in the study by advertisements in newsletters of local parent-child associations. The mean age of the mothers at the start of the study was 28 years and that of the fathers was 30 years. The infants were seen at 6,12 , and 30 months. Seven infants did not return for the 12-month assessment because of scheduling difficulties or because the families had moved from the area. This left 68 subjects at 12 months, 36 boys and 32 girls. When the children were 30 -months old, 53 participated, 32 boys and 21 girls. Again the attrition was due to scheduling problems or the families moving away from the immediate area.

\section{Procedure}

At 6 and 12 months the procedures were almost identical. The infants were brought to our laboratory playroom on three occasions within 1 week of their 6- or 12-month birthdays. The first visit included an as- sessment of the infant's developmental status using the Bayley Scales of Infant Development (Bayley, 1969). This was administered by a male examiner. On the other two visits, the infant was presented with the experimental mastery assessment tasks developed in our laboratory (Vietze et al., 1978). These consisted of 12 tasks that had been selected for their age appropriateness and their ability to elicit exploratory behavior. Each task had a goal or outcome that could be achieved. For example, obtaining the object from behind or under the barrier was the goal or successful performance of the Problem Solving tasks. The tasks were divided into three groups, with each group of four tasks requiring the performance of similar activities. The reasons and justification for grouping these tasks has been discussed by Yarrow et al. (1983). The Effect Production tasks allowed the infant to operate a manipulandum in order to produce some sensory effect, either auditory, visual, or both. An example of this kind of task at 6 months was pulling a string to ring a bell. At 12 months, one task of this variety allowed the infant to operate one of a number of manipulanda to make a door pop open, revealing a small figure. The Practicing Sensorimotor Skills tasks consisted of activities in which the infant could remove objects from a container at 6 months and place objects into a container at 12 months. The Problem Solving tasks entailed the infant's obtaining an object that was out of reach or behind a barrier. For example, to obtain the object the infant had to reach around a transparent screen or lift a cloth. Although the tasks were different for 6- and 12-month assessments, their structure and procedures were similar. A complete list of the tasks for both ages and their descriptions is provided in Yarrow et al. (1983).

The tasks were administered, six on each of 2 days, by one of two female examiners. During the session, the infant sat on his or her mother's lap at a feeding table across from the examiner. Each session was videotaped from behind a one-way mirror. After two warm-up items, each task was presented to the infant by the examiner for $3 \mathrm{~min}$. In presenting the item to the infant, the examiner first demonstrated the item and then said, "Can you do it?" Unlike standard procedures for administering developmental tests in which the examiner attempts to motivate the child in order to obtain optimal performance, the mother and examiner kept from interacting with the child or encouraging him or her during the 3min period.

The videotapes were coded using an electronic digital recording device (Datamyte 900, Electro-General Corporation), which enables analysis of the sequence and duration of behaviors. The coding scheme used to code the tapes is provided in Table 1 (social behavior was also coded but is not considered in this article). The behaviors were mutually exclusive and exhaustive. Thus, the total time of an infant's engagement in a task was equal to the total time obtained from the behavioral codes. The raw data were the number of seconds the child was engaged in each of the behaviors. 
Mastery variables. In order to reduce the number of variables, the behaviors were collapsed to form five levels of task involvement. These are indicated in Table 1 along with their component parts. Visual Attention without manipulation was considered the lowest level of task involvement. Peripheral Exploration consisted of only limited contact with the task. Infants would use one behavior from their repertoire such as mouthing or touching to explore an object. General Exploration occurred when the infants used two or more behaviors in concert such as mouthing and looking to explore an object. Task-Directed behavior consisted of activities that were attempts to master the object but were not appropriate for accomplishing the goal of the task, or that consisted of holding a part of the toy or object that might be used to achieve the goal. Goal-Directed behavior consisted either of action that could lead to mastery of the toy or of resetting the task so that the goal might be reached again. A previous analysis of the 6- and 12-month data has already been reported (Yarrow et al., 1983). Our levels of task involvement correspond to the behavior categories used in this previous study, but include subdivisions of their categories. Visual Attention is the same in both analyses; our Peripheral and General Exploration levels of task involvement together correspond to Exploratory Behavior in Yarrow et al. (1983); and our Task- and GoalDirected levels together correspond to the Persistence Behavior of Yarrow et al. Interrater reliability was obtained by having two observers independently code all 12 tasks for 18 subjects. The Pearson product-moment correlations between observers for the duration of each level of task involvement were: Visual Attention, .78; Peripheral Exploration, .61; General Exploration, .92; Task-Directed Behavior, .88; and Goal-Directed Behavior, .78.

The percentage of time that each behavior lasted is the measure used in our analyses. Because the behaviors were mutually exclusive, if one percentage was high the others had to be low. Thus, correlations of these behaviors with other data might show that if one behavior was positively correlated, another might be negatively correlated. This is not necessarily so but, as will be seen, sometimes occurred. Thus, it is important to consider patterns of correlation rather than concentrating on one or two variables.

Assessment at 30 months. At 30 months the infants were administered the McCarthy Scales of Children's Abilities (McCarthy, 1972) in a playroom at our laboratory. This test of developmental competence provides an overall score of General Cognitive Development together with scores on separate Motor and Memory subscales. The General Cognitive score is calculated from the child's performance on the Verbal, Qualitative, and Perceptual performance items. The children were tested by one of two female examiners.

\section{Results}

The percentage duration of the levels of task involvement are given in Table 1. Yarrow et al. (1983) have already analyzed the relation between 6- and 12-month mastery behavior. This revealed a complex set of correlations suggesting that mastery behavior undergoes some qualitative change over this period. Correlations were calculated between the Bayley Scales at 6 and 12 months and the McCarthy Scales at 30 months. There were mostly low, nonsignificant positive correlations between the Bayley scores obtained during infancy and the General Cognitive, Memory, and Motor McCarthy scores at 30 months (see Tables 2 and 3; the only significant correlation was for 6-month-old girls, between the Bayley Mental Index and the 30-month Motor scales, $r=.46$ ). Such results are in agreement with other studies with nondelayed children, which have for the most part failed to find continuity in scores on developmental tests between infancy and early childhood.
Correlations also were calculated between the frequency of success on the tasks and later developmental competence. Success was considered to occur when the infant achieved one of the goals posed by the toy, for example, operating a manipulanda to make a small figure emerge from behind a door. The number of significant correlations between early success and later developmental competence was similar to that expected by chance. For girls at 12 months, both success on Effect Production and on Practicing Sensorimotor Skills were correlated with the later Memory score on the McCarthy Scales $(r=.37$ and .38, respectively). For boys at 6 months, success on Practicing Sensorimotor Skills was correlated with the General Cognitive and the Verbal scales of the McCarthy test $(r=.36)$. Thus, the infant's success on these tasks did not assist predicting their later ability.

The correlations between task involvement at 6 months and later developmental competence are given in Table 2 . It has been suggested that the three groups of mastery tasks can be differentiated in terms of their complexity and predictive relations (Yarrow et al., 1983), Effect Production being the lowest level and Problem Solving being the highest level. Because of this, the findings are presented according to both the level of behavior and the form of the tasks.

The findings reveal differences in patterns of correlations for the tasks and the two sexes. The correlations of task involvement with the McCarthy scores tended to be higher for girls than boys. At 6 months the correlations for girls were more extreme and significantly different from those of boys in 16 out of $45 \mathrm{com}$ parisons ( 45 comparisons $=15$ levels of task involvement times the 3 McCarthy scores, General Cognitive, Memory, and Motor); only in 8 cases was the reverse true (i.e., the boys' correlation was significantly more extreme than that of the girls; $p<0.05$; Guilford, 1965, p. 189). Another notable feature of Table 2 was that some of the less directed forms of task involvement were highly correlated with later competence. Girls who visually attend to objects, girls who engage in peripheral exploration, and girls and boys who engage in general exploration tended to be more developmentally advanced at 30 months. In contrast, for both girls and boys, the percentage of time spent in Task-Directed Behavior was strongly negatively correlated with later competence, and Goal-Directed Behavior tended to be negatively correlated with later competence.

At 6 months, children who engaged in less directed forms of task involvement had higher scores on the McCarthy Scales. Why should this be? On an a priori basis, one would expect that children who spend time on apparently more sophisticated taskrelated activities should be the ones who are later more developmentally advanced. We consider possible answers to this question in the Discussion.

At 12 months, as at the younger age, significant correlations were mostly confined to girls (see Table 3). The correlations for girls were more extreme and significantly different from those of boys in 23 of 45 comparisons (involving the 15 levels of task involvement and $3 \mathrm{McC}$ arthy scores; $p<0.05$ ); only in 8 cases was the reverse true. In addition, at 12 months there were fewer significant correlations than at 6 months (16 significant correlations at 6 months compared to 7 at 12 months). Moreover, the direction of the relations had changed. The less directed forms of task involvement were, unlike at 6 months, negatively related to later competence. For girls, Visual Attention, Peripheral Ex- 
Table 2

Correlations Between Task Involvement at 6 Months and Later Developmental Competence, by Sex and Component

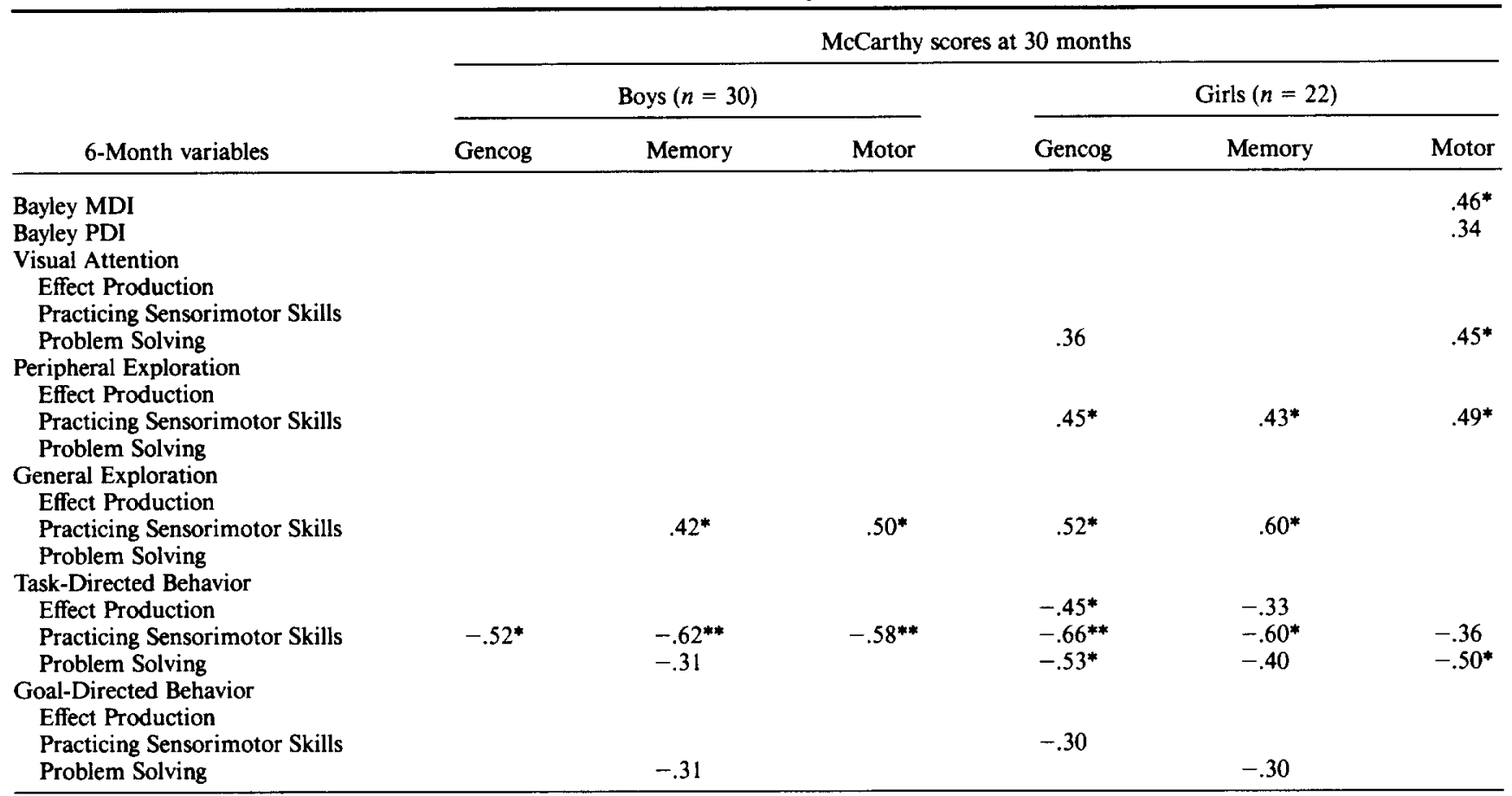

Note. Only correlations $\geq .30$ are included in this table. Gencog $=$ General Cognitive. MDI $=$ Mental Development Index. PDI $=$ Psychomotor Development Index.

${ }^{*} p<.05{ }^{* *} p<.01$.

Table 3

Correlations Between Task Involvement at 12 Months and Later Developmental Competence, by Sex and Component

\begin{tabular}{|c|c|c|c|c|c|c|}
\hline \multirow[b]{3}{*}{ 12-Month variables } & \multicolumn{6}{|c|}{ McCarthy scores at 30 months } \\
\hline & \multicolumn{3}{|c|}{ Boys $(n=30)$} & \multicolumn{3}{|c|}{ Girls $(n=19)$} \\
\hline & Gencog & Memory & Motor & Gencog & Memory & Motor \\
\hline $\begin{array}{l}\text { Bayley MDI } \\
\text { Bayley PDI } \\
\text { Visual Attention }\end{array}$ & & & & & & \\
\hline $\begin{array}{l}\text { Effect Production } \\
\text { Practicing Sensorimotor Skills } \\
\text { Problem Solving }\end{array}$ & $\begin{array}{l}.30 \\
.31\end{array}$ & $\begin{array}{l}.38^{*} \\
.33 \\
.45^{*}\end{array}$ & & & $\begin{array}{l}-.55^{*} \\
-.49^{*}\end{array}$ & -.44 \\
\hline \multicolumn{7}{|l|}{ Peripheral Exploration } \\
\hline $\begin{array}{l}\text { Practicing Sensorimotor Skills } \\
\text { Problem Solving }\end{array}$ & & & & .30 & -.32 & -.36 \\
\hline \multicolumn{7}{|l|}{ General Exploration } \\
\hline $\begin{array}{l}\text { Practicing Sensorimotor Skills } \\
\text { Problem Solving }\end{array}$ & & & .34 & -.43 & & $-.48^{*}$ \\
\hline $\begin{array}{l}\text { Task-Related Behavior } \\
\text { Effect Production } \\
\text { Practicing Sensorimotor Skills } \\
\text { Problem Solving }\end{array}$ & & & & & & .40 \\
\hline $\begin{array}{l}\text { Goal-Directed Behavior } \\
\text { Effect Production }\end{array}$ & & & & & & \\
\hline Practicing Sensorimotor Skills & & & & $.48^{*}$ & .36 & $.46^{*}$ \\
\hline Problem Solving & & & & .38 & .30 & .41 \\
\hline
\end{tabular}

Note. Only correlations $\geq .30$ are included in this table. Gencog $=$ General Cognitive. MDI $=$ Mental Development Index. PDI $=$ Psychomotor Development Index.

$* p<.05$. 
ploration, and General Exploration were negatively related to some of the later McCarthy scores. In contrast, Goal-Directed Behavior was significantly positively related to later competence. In other words, for the girls, less directed levels of task involvement were negatively related to the McCarthy scores, whereas the highest level, Goal-Directed Behavior, was positively related. For boys, there were fewer significant correlations. Furthermore, Looking Without Manipulation was the main behavior found to be positively related to later competence. This may be because for boys, Visual Attention is a higher level of reflective or contemplative behavior.

One issue of interest is whether the levels of task involvement had significantly higher correlations with the McCarthy Scales than the Bayley Mental Development Index (MDI) and Psychomotor Development Index (PDI) scores. This issue was investigated using Hotelling's test ( $p<0.05$, two-tailed; Guilford, 1965), with $r_{12}$ and $r_{13}$ being assigned the same sign. At 6 months, for boys with Practicing Sensorimotor Skills tasks, General Exploration had a significantly higher correlation with the 30 -month Motor scale than the MDI, and Task-Directed Behavior had significantly higher correlations with the Memory and Motor scales than the MDI. For girls at this age, Task-Directed Behavior on Practicing Sensorimotor Skills tasks was a significantly better predictor of the General Cognitive and Memory scales than the MDI. On the other hand, for the girls the MDI was a better predictor of the Motor scale than Peripheral Exploration on Effect-Production tasks. At 12 months there were fewer significant differences. For boys, only Task-Related Behavior with Practicing Sensorimotor Skills tasks had a significantly higher correlation than the MDI with the General Cognitive scale. For girls, GoalDirected Behavior with tasks involving Practicing Sensorimotor Skills had significantly higher correlations with the General Cognitive and Motor scales.

Similar comparisons were made between the levels of task involvement and the PDI. At 6 months, for Practicing Sensorimotor Skills tasks with boys, General Exploration was a significantly better predictor than the PDI of the Motor scale, and Task-Directed Behavior had significantly higher correlations with the General Cognitive and Motor scales. For girls at this age, on tasks involving Practicing Sensorimotor Skills, General Exploration was a significantly better predictor than the PDI of the Memory scale, whereas Goal-Directed Behavior had significantly higher correlations with the General Cognitive and Memory scales. At 12 months the only significant difference was that GoalDirected behavior by girls on Practicing Sensorimotor Skills tasks was a significantly better predictor of the General Cognitive scale than was the PDI. Thus, these comparisons of the correlations confirm the picture that was apparent from the simple inspection of Tables 2 and 3; that is, in some cases the levels of task involvement provided better predictors of later competence than the Bayley scores.

We also wanted to determine whether the correlations between the levels of involvement and the McCarthy Scales were generally higher than the correlation between the Bayley MDI and the McCarthy Scales. To answer this question, 12 sets of comparisons were made according to the child's sex (2), the child's age (2), and the McCarthy Scales (3). In these 12 comparisons it was determined whether each of the 15 measures of task involvement had a higher correlation with a particular scale of the McCarthy than the correlation between the Bayley MDI and the McCarthy Scales. The levels of task involvement had consistently higher correlations with the McCarthy scores than the MDI, at both 6 and 12 months (the only exceptions in the 12 comparisons were the prediction of the 30-month Motor score for 6-month-old boys, the 30-month Motor score for 12-month-old girls, and the prediction of the 30-month General Cognitive score for 12month-old girls). In all other cases there were at least 9 correlations from the levels of task involvement that were higher than the MDI; for four comparisons the numbers were significantly greater than would be expected by chance (the prediction of the General Cognitive and Motor scores for 6-month-old boys, the prediction of the General Cognitive score for 12-month-old boys, and the prediction of the 30-month Motor score for 12-monthold girls; $p<.05$, two-tailed sign test).

To address, in a slightly different way, the differential utility of Bayley scores and levels of task involvement as predictors of 30-month McCarthy scores, we conducted several sets of multiple-regression analyses. These analyses were based on scores from the total group and were performed in a modified stepwise fashion. Regressions were done in pairs for each dependent variable; in the first regression, the set of mastery variables was entered first, followed by the set of Bayley variables, while the order was reversed in the second regression-Bayley variables entered first followed by mastery variables. All variables in each set (i.e., mastery or Bayley) were forced into the equation, and the change in $R^{2}$ in each case was then examined to ascertain whether the contribution of either set of variables represented a significant increase in explanatory power over the other set. For each of the 30-month McCarthy scores (General Cognitive, Memory, Motor), two pairs of regression analyses were computed, one pair using 6-month Bayley scores and levels of task involvement as predictors, the other using these same measures at 12 months. None of the regression pairs using the 12-month measures showed significant increases in $R^{2}$ for either mastery or Bayley variables; however, as Table 4 shows, for two of the three regression pairs using the 6-month measures, the set of mastery variables provided a significant increase in $R^{2}$ over the Bayley variables. In no case did the Bayley variables provide a significant increase from $R^{2}$ over the mastery variables.

\section{Discussion}

These findings suggest that predictability exists between the infants' mastery behavior and their later cognitive functioning. In the majority of cases the relations were stronger for girls than they were for boys. This is consistent with other studies that have examined continuities in developmental competence (Bayley \& Schaefer, 1964; Honzik, 1976; Jennings et al., 1981; McCall et al, 1972). We believe that these differences may be partly caused by the 30 -month-old boys' behavior being more variable. They appeared more likely to refuse to attempt some McCarthy tasks while becoming involved in others.

The findings also suggest that there may be a transformation in the nature of mastery behavior between 6 and 12 months. The interpretation of the transformations is helped by considering the infants' level of cognitive functioning. Piaget's (1952) work indicates that at 6 months the infants are likely to be in Stage 3 of the sensorimotor period (secondary circular reactions). They 
Table 4

Results of Regression Analyses Using Bayley Scores and Levels of Task Involvement at 6 Months to Predict 30-Month McCarthy Scores

\begin{tabular}{|c|c|c|c|c|c|c|}
\hline Step-dependent & Independent & Multiple $R$ & $R^{2}$ & $R^{2}$ change & $F$ & $\begin{array}{c}\text { Increase in variance } \\
\text { explained }\end{array}$ \\
\hline General cognitive & $\begin{array}{l}\text { Bayley } \\
\text { Mastery }\end{array}$ & $\begin{array}{l}.17 \\
.76\end{array}$ & $\begin{array}{l}.03 \\
.57\end{array}$ & $\begin{array}{l}.03 \\
.55\end{array}$ & $\begin{array}{l}0.73 \\
3.67\end{array}$ & $F(12,38)=4.07^{*}$ \\
\hline Memory & $\begin{array}{l}\text { Bayley } \\
\text { Mastery }\end{array}$ & $\begin{array}{l}.20 \\
.79\end{array}$ & $\begin{array}{l}.04 \\
.63\end{array}$ & $\begin{array}{l}.04 \\
.59\end{array}$ & $\begin{array}{l}1.10 \\
4.64\end{array}$ & $F(12,38)=5.06^{*}$ \\
\hline Motor & $\begin{array}{l}\text { Mastery } \\
\text { Bayley }\end{array}$ & $\begin{array}{l}.60 \\
.61\end{array}$ & $\begin{array}{l}.36 \\
.38\end{array}$ & $\begin{array}{l}.36 \\
.02\end{array}$ & $\begin{array}{l}1.87 \\
1.63\end{array}$ & $F(2,38)=.52, n s$ \\
\hline
\end{tabular}

Note. The set of mastery variables included four levels of task involvement (general exploration, task-directed behavior, goal-directed behavior, and success) for each of the three task components (effect production, practicing sensorimotor skills, and problem solving). The set of Bayley variables included the Mental Development Index and the Motor Development Index.

$* p<.001$.

explore by using their established repertoire of actions on new objects; they will mouth, manipulate, shake, and bat objects. They do not have the ability to identify means-ends relations, so they are unlikely to identify the actions that will result in success in a task.

Thus, it is possible that at 6 months the levels of task involvement do not fully reflect infants' mastery behavior. Inspection of the coding scheme tends to support this idea. Peripheral and General Exploratory behavior consisted of manipulating, examining, shaking, hitting, rejecting, or offering an object or part of a toy. The way Piaget describes 6-month-old infants' attempts to investigate an object corresponds to our Exploratory Behavior. When account is taken of the way that 6-month-olds attempt to master objects, the relation between exploratory behavior at 6 months and later developmental competence becomes understandable.

At 6 months there were also strong negative correlations between the higher levels of task involvement and later competence. To a large extent these findings are different faces of the same coin. Given our coding scheme, strong positive correlations on one dimension may entail strong negative correlations on another dimension. In addition, task-related behavior consisted of activities that would, in theory, represent more directed forms of task involvement. However, because infants of this age may lack appropriate understanding of means-ends relations, it is questionable whether this was the case. The 6-month-old infants may have been following their own agenda of exploring the toy, whereas older children may follow the goals posed by the tasks. In addition, we suspect that Task-Directed and Goal-Directed Behavior at 6 months may include undifferentiated activity. This is because Task-Directed behavior could include gross actions that would precede mastery attempts or even perseverative behavior.
At 12 months, infants can recognize the means to achieve an end. Consequently, at this stage of cognitive development Peripheral and General Exploration reflect less directed forms of task involvement, and it is not surprising that they were negatively related to later McCarthy scores. In contrast, Goal-Directed Behavior, which represents the highest form of task directedness, was positively related to later competence.

In general, the correlations are weaker at 12 months than at 6 months. There are a number of possible explanations for this. One explanation we favor on the basis of impressions obtained from coding and from our view of mastery is that mastery behavior becomes more differentiated and complex with increasing age. As a result, in early infancy there are only a limited number of ways for infants to master the environment, but by the end of the first year there may be a greater variety of approaches that could be used for mastery attempts. As a result it may be more difficult to infer the children's motivation from their mastery behavior, and this may produce a greater degree of error in the measurement process. If this interpretation is correct, it is advisable for future studies to collect an even more detailed record of behavior at 12 months.

These findings suggest that the way an infant attempts to master a problem may predict later development more effectively than does the infant's level of competence. Infants who attempted to master objects in a way appropriate for their level of cognitive functioning were the ones who later had higher scores on the McCarthy Scales. It would appear that children who have or acquire a disposition to gain knowledge and skills will increase the likelihood of higher competence in later life. Thus, the tendency to master problems may be an important process for development. Given that this is a correlational study, there may be other possible explanations for these relations. Consequently, we should be careful before accepting the interpretation that mastery 
behavior in infancy leads to later competence. Rather, the identification of these relations should stimulate further research aimed at discovering both the variables that influence the expression of mastery behavior and its importance for development.

\section{References}

Bayley, N. (1955). On the growth of intelligence. American Psychologist, 10, 805-814.

Bayley, N. (1969). Bayley scales of infant development. New York: Psychological Corporation.

Bayley, N., \& Shaefer, E. S. (1964). Correlations of maternal and child behaviors with the development of mental abilty: data from the Berkeley Growth Study. Monographs of the Society for Research in Child Development, 29(6, Whole No. 97).

Bronson, W. C. (1971). The growth of competence: Issues of conceptualization and measurement. In H. R. Schaffer (Ed.), The origins of human social relations (pp. 269-280). New York: Academic Press.

Bruner, J. S. (1973). The organization of early skilled action. Child Development, 44, 1-11.

Gesell, A. (1925). The mental growth of the pre-school child. New York: MacMillan.

Guilford, G. J. P. (1965). Fundamental statistics in psychology and education. London: McGraw-Hill.

Honzik, M. P. (1976). Value and limitations of infant tests: An overview. In M. Lewis (Ed.), Origins of intelligence (pp. 59-95). New York: Plenum Press.

Hunt, J. M. (1963). Motivation inherent in information processing and action. In O. J. Harvey (Ed.), Motivation and social action (pp. 3595). New York: Ronald Press.

Hunt, J. M. (1965). Intrinsic motivation and its role in psychological development. In D. Levine (Ed.), Nebraska Symposium on Motivation (Vol. 13, pp. 189-282). Lincoln: University of Nebraska Press.

Jennings, K. D., Yarrow, L. J., \& Martin, P. P. (1981). Mastery motivation and cognitive development: $A$ longitudinal study from infancy to three and one half years. Unpublished manuscript, University of Pittsburgh.
Lewis, M., \& Goldberg, S. (1969). Perceptual-cognitive development in infancy: A generalized expectancy model as a function of the motherinfant interaction. Merrill-Palmer Quarterly, 15, 81-100.

McCall, R. B. (1979). The development of intellectual functioning in infancy and the prediction of later I.Q. In J. D. Osofsky (Ed.), Handbook of infant development (pp. 707-741). New York: Wiley.

McCall, R. B., Hogarty, P. S., \& Hurlburt, N. (1972). Transitions in infant sensorimotor development and the prediction of childhood I.Q. American Psychologist, 27, 728-748.

McCarthy, D. (1972). Manual for the McCarthy scales of children's abilities. New York: Psychological Corporation.

Piaget, J. (1952). The origins of intelligence in the child. New York: International University Press.

Vietze, P. M., Pasnak, C. F., Tremblay, D., McCarthy, M. E., Klein, R. P., \& Yarrow, L. J. (1978). A manual for assessing mastery motivation in 6 and 12 month old infants. Unpublished manuscript.

Watson, J. S. (1966). The development and generalization of contingency awareness in early infancy: Some hypotheses. Merrill-Palmer Quarterly, $12,123-135$.

Watson, J. S. (1972). Smiling, cooing and "The Game." Merrill-Palmer Quarterly, 18, 323-329.

White, R. W. (1959). Motivation reconsidered: The concept of competence. Psychological Review, 66, 297-333.

White, R. W. (1963). Ego and reality in psychoanalytic theory. Psychological Issues, 3, 1-40.

Yarrow, L. J., McQuiston, S., MacTurk, R. H., McCarthy, M. E., Klein, R. P., \& Vietze, P. M. (1983). Assessment of mastery motivation during the first year of life: Contemporaneous and cross-age relationships. Developmental Psychology, 19, 159-171.

Yarrow, L. J., \& Pedersen, F. A. (1976). The interplay between cognition and motivation in infancy. In M. Lewis (Ed.), Origins of intelligence (pp. 379-399). New York: Plenum Press.

Received May 24, 1984

Revision received August 28, 1985 